\title{
Gender-Based Drink Stereotypes and Consumption Intentions: A Study With the U.S. Millennials
}

\author{
Musa Pinar \\ Valparaiso University \\ Ceren Ekebas-Turedi \\ Purdue University Northwest \\ Cigdem Basfirinci \\ Trabzon University
}

\begin{abstract}
This study examines (1) the gender-based drink stereotypes to determine if drinks are perceived as feminine, masculine, or gender-neutral by millennials in the U.S. and (2) investigates the consumption intentions of male and female millennials per gender-drink stereotypes. A survey instrument was designed to address the study objectives. Results showed that some drinks were perceived as masculine and others as feminine, revealing that gender-based drink stereotypes exist among millennials. The results also confirmed the expected relationship between gender-based drink stereotypes and consumption intentions of the stereotyped drinks. These findings of the study have managerial implications for segmentation, positioning, and developing marketing and promotional strategies.
\end{abstract}

Keywords: gender-based drink stereotypes, masculine and feminine drinks, millennial consumers, consumption intentions

\section{INTRODUCTION}

In modern consumption culture, the categories of products serve as a reference point for consumers in creating a gendered identity (Thompson and Holt, 2004). Hence, the supermarket shelves are filled with different drinks that reflect gendered identities with such features as the content of the product, the packaging design, and the colors used in the brand, all of which reflect the possible gender-based drink stereotypes. Research by Ulrich and Tissier-Desbordes (2018) indicates that consumers use gender norms and stereotypes in deciding which products and brands they should purchase and consume to express their gendered identities. Drake et al. (2018) suggest that gender is one of the most important social categorizations in human life, such that gender is "a filter through which individuals experience their social world" (Bristor and Fischer, 1993, 519). In this regard, the concept of gender becomes functional through gender stereotypes.

Murcott (1983) states that consumption of food conveys multilayered meanings in social life that offers ways for communication, social interaction, and identity expression. Gender-based food meaning is among 
these multilayered meanings, serving as an important signal for gender identity (Basfirinci and Cilingir Uk, 2017). Therefore, certain food items are associated with specific genders, in a way that the genders of the consumers influence their food consumption preferences (Counihan and Kaplan, 2004). We expect that, similar to gender-based food items, there can be gendered-based drink stereotypes, such that drinks can be perceived as masculine, feminine, or gender-neutral, which in turn, could influence the consumption intentions of the consumer. To the best of our knowledge, no study investigates the gendered meaning of drinks. Therefore, this study intends to fill this gap by examining the gender-based drink stereotypes among millennials in the U.S. and the influence of the stereotyped drinks on consumption intentions, and if these consumption intentions differ by millennials' gender.

\section{THEORETICAL BACKGROUND}

Butler (2002) has described the gender stereotypes as widely shared strong beliefs and generalized expectations of the society that certain attributes and so-called appropriate roles attribute to differentiate men and women in different cultures. Theoretical roots of gender stereotypes mainly draw on Eagly's social role theory (Diekman and Eagly, 2000; Eagly, 1987) and the cognitive theory of gender development and differentiation (Bussey and Bandura, 1999). These theories suggest that gender roles are the product of traditional roles and a broad network of social influences operating interdependently in a variety of societal subsystems. In addition, self-congruity theory links the gender-based stereotype perceptions of an individual with the consumption tendency (e.g., Neale et al., 2016; Ulrich and TissierDesbordes, 2018). The self-congruity theory is derived from Mandler's (1982) schema congruity theory used to predict the effect of similarity perceptions. The theory suggests that when a stimulus is perceived congruent with a schema, it leads to meaning transfer and favorable response. Therefore, the self-congruity theory predicts that, in seeking self-consistency, individuals would prefer some specific products, drinks in this study, that are congruent with gender perceptions of their self-concepts (Basfirinci and Cilingir Uk, 2017). In this regard, gender-based market segmentation and promotion strategies are commonly used practices, especially in the rapidly growing food and beverage industry. Food and drink consumption preferences can differ for the members of each gender. Given that drink consumption preferences could be influenced by gendered stereotypes, this could lead to the segmentation of the food and beverage products by gendered identities.

Gender-based food stereotypes have been well studied in the literature. Previous research indicates that some foods such as beef, hamburgers, and potatoes are perceived as masculine foods, whereas vegetables, salads, yogurt, fruit, and chocolate are perceived as feminine foods (Bourdieu, 1984; Bove et al., 2003; Dickens and Chappell, 1977; Jensen and Holm, 1999; Lupton, 1996). Moreover, the extant literature indicates that foods are not only perceived as either masculine or feminine but also used in maintaining and exhibiting gendered identity (e.g., Basfirinci and Cilingir Uk, 2017; Cavazza et al., 2015; Diekman and Eagly, 2000; D'Sylva and Beagan, 2011; McPhail et al., 2012; Turner et al., 2013; Vartanian et al., 2007; Young et al., 2009). These studies indicate the existence of widespread gender-based stereotypes about food items such as meat being masculine food in almost every culture (Sobal, 2005). In addition, research showed that people show different food preferences when the concept of masculinity or femininity is brought up (Basfirinci and Cilingir, 2017; Bove et al., 2003; Holtzman, 2018; McPhail et al., 2012; Sobal, 2005) and gender-based food stereotypes exist and to the extent that individuals prefer to eat gender congruent food (Cavazza et al., 2015). A recent study by Ekebas-Turedi et al. (2020) investigates whether gender-based food stereotypes exist among millennial consumers of two different cultures and shows that respondents perceive certain foods as masculine and feminine, but the degree of masculinity or femininity and food consumption intentions differs by gender and country.

Even though there are various studies on food-gender stereotypes, prior studies concerning genderbased drink stereotyping mainly focus on alcohol consumption and their gender relationships (e.g., Ely et al., 1999; George et al., 1988; McDonald, 1994; Murphy et al., 2005; Wilsnack et al., 2000). For example, a study by Murphy et al. (2005) examined the impact of alcohol use and alcohol-related problems on several domains of life satisfaction. The results show that alcohol use was associated with lower general satisfaction 
and anticipated future satisfaction among women, where female abstainers reported higher general and anticipated future satisfaction than female heavy drinkers. Their findings suggest that alcohol use by young adults is associated with both positive and negative outcomes. Dempster (2011), who examined the role of alcohol in communicating hegemonic masculinity, found that male students' heavy alcohol use is partially motivated by discourses. He also indicates that this positions drinking as a 'normal' part of student-hood, yet reinforcing drinking as a 'laddish' behavior or a male preserve and recognizing the importance of drinking in constructing masculinity. His study highlights the complex and somewhat contradictory processes individuals go through in the construction of gender identities. A study by Deliens et al. (2015) found that gender as a control variable was negatively associated with energy drink consumption, such that female students consumed fewer energy drinks than their male counterparts.

Concerning gender-drink preference; thus, stereotyping, Cooper (2017) points out that market data support the contention that some of the long-established gender-based consumer preferences are breaking down. He indicates that around $15 \%$ of craft beer drinkers in the US are women, with women also accounting for more than $25 \%$ of total beer consumption. The same data indicates that while only $15 \%$ of whiskey drinkers in the US were women twenty years ago, today, it is $27 \%$. The proportion of female whiskey drinkers has increased by nearly $150 \%$ in two decades. These consumption figures show that, as Cooper (2017) points out, it does not take a huge leap in imagination to predict the complete de-gendering of drinks occurring in the near future. Also, Allen (2017) stated that once upon a time, pink wine and gin were considered ladies' drinks, but now, all that is changed, such that the revival of gin and rose are two of the biggest drink trends (in Australia) right now. When the global rosé revival kicked off in Europe and the United States several years ago, he points out that retailers, bartenders, and restaurateurs started noticing how many young men were ordering the pink drink, as were young women; this consumer category even earned its own nickname: brosé. This shows a changing perception of gender-drink preferences and stereotypes.

According to a 2019 survey (Conway, 2020), 43\% of females and $22 \%$ of males chose wine as their favorite alcoholic beverage. For beer, though, the preference difference was larger where $38 \%$ of males and only $15.6 \%$ of females chose beer, while liquor and spirits seem to be equally preferred with $39.3 \%$ of males and $41.2 \%$ of females. In addition, the results from Gallup's Consumption Habits (Saad, 2019) survey with U.S. national adults aged 18 and older, found that beer is the most preferred drink with $55 \%$ by males, which is $21 \%$ by females, while wine is the most preferred drink with $45 \%$ by females, and $15 \%$ by males. These findings support the existence of gender-based drink stereotypes for the most popular alcoholic beverages in the US. Although the prior studies provide some perspective about drinking preferences and trends, they did not examine the perception of gender-based drink stereotypes and consumption intentions.

To the best of our knowledge, there is no comprehensive research examining gender-based drink stereotypes covering all drink categories, such as alcoholic or non-alcoholic, for younger generations such as millennials. Therefore, this study investigates the perceptions of gender-based stereotypes of various drinks as masculine or feminine among the U.S. millennials (students) and their consumption intentions of the gender-stereotyped drinks. This study does not intend to address why the drinks are perceived as masculine or feminine; rather aims to address the gender-based perceptions of the drinks included in the study. The specific objectives of the current study are to:

1. Examine whether the perception of gender-drink stereotyping exists among millennials, such that some drinks are considered as masculine, feminine, or gender-neutral by all respondents and by each gender (men and women).

2. Determine whether perceptions of gender-drink stereotyping significantly differ by respondents' gender.

3. Investigate if respondents' consumption tendencies of these drinks are consistent with gender stereotypes by each gender and determine if consumption tendencies differ by respondent's gender. 


\section{METHODOLOGY}

To accomplish the objectives, several steps were taken to create a list of drinks to be used in the study. In step 1, qualitative research was conducted among college students to define drinks that were perceived as masculine, feminine, or gender-neutral. Male and female students were asked to provide both 5-8 alcoholic and non-alcoholic drinks that they perceived as masculine, feminine, and gender-neutral using open-ended questions. The results from 45 students ( 21 males and 24 females) generated a list of masculine, feminine, and gender-neutral drinks. Next, these items were pretested with 114 students (53 males and 61 females) to determine if they are perceived as masculine, feminine, or gender-neutral (5-point scale ranging from $-2=$ definitely feminine, $0=$ gender neutral to $2=$ definitely masculine). The pretests provided further insights for improvement of the questions and the face validity of the statements to be included in the final survey (Churchill and Iacobucci, 2005). Based on the pretest, the results identified 14 drinks (both alcoholic and non-alcoholic) that are perceived as masculine, feminine, or gender-neutral. Gender-drink stereotyping and consumption tendencies are measured with a 5-point scale, the stereotyping scale ranged from $2=$ definitely feminine, $0=$ gender neutral, and $2=$ definitely masculine, whereas consumption tendency ranged from $-2=$ very unlikely to $0=$ neither unlikely or likely to $+2=$ very likely. The survey also included demographic questions of gender and age.

Following Naderi and Van Steenburg (2018), college students were selected as subjects because they represent the millennials (in terms of age) in the U.S. In the final study, the subjects were students from two universities in the U.S. The survey link was sent to students with the help of professors teaching various courses at different class levels. Two week period was given to completed the survey. Students were compensated for their participation by being entered into a drawing for six $\$ 25$ gift cards. The survey also included demographic questions. The final sample size was 418 respondents $(52.4 \%$ male, $47.6 \%$ female, average age: 21.3 years).

\section{RESULTS}

Based on an initial analysis, the study excluded drinks that were perceived as gender-neutral (milk, tea, coffee, and water) and included only masculine and feminine drinks for further analysis focus on gender effects on these drinks. Firstly, we examined if the perception of gender-based drink stereotypes exists among millennials by using a one-sample t-test with test value $=0$ on a 5 -point interval scale to determine this for all respondents. Table 1 shows that all drinks included in the study are statistically different from zero $(\mathrm{p}<.01)$, the midpoint of the scale, indicating the existence of gender-based drink stereotypes among millennials. The results show that for all respondents, diet soda, iced tea, and fruit juices are perceived as feminine non-alcoholic drinks, and soda, energy drinks, and protein shakes are as masculine non-alcoholic drinks, whereas wine and mixed alcoholic drinks are perceived as feminine drinks and whisky and beer as masculine alcoholic drinks. The results for men and women follow similar patterns (See Table 1) with different magnitudes of masculinity or femininity perception. It appears that among the non-alcoholic drinks, diet soda is perceived as the most feminine drink, and protein shake is the most masculine, whereas wine is perceived as the most feminine and beer is the most masculine alcoholic drink. Since the perceptions of these drinks follow similar patterns for male and female respondents, this suggests that both genders have similar perceptions regarding gender-based stereotypes of these drinks. 
TABLE 1

GENDER-BASED DRINK STEREOTYPES AMONG THE U.S. MILLENIALS

\begin{tabular}{|c|c|c|c|c|c|c|c|c|c|c|}
\hline & \multicolumn{10}{|c|}{ Respondents } \\
\hline & \multirow[b]{2}{*}{ Drinks } & \multicolumn{3}{|c|}{ All Respondents } & \multicolumn{3}{|l|}{ Male } & \multicolumn{3}{|c|}{ Female } \\
\hline & & Mean & $\begin{array}{l}\text { Std. } \\
\text { Dev. }\end{array}$ & p-sig. & Mean & $\begin{array}{l}\text { Std. } \\
\text { Dev. }\end{array}$ & p-sig. & Mean & $\begin{array}{l}\text { Std. } \\
\text { Dev. }\end{array}$ & p-sig. \\
\hline \multirow{6}{*}{$\begin{array}{l}.0 \\
0 \\
0 \\
0 \\
0 \\
\frac{0}{T} \\
1 \\
0 \\
z \\
z\end{array}$} & Diet Soda & -0.59 & 0.71 & 0.000 & -0.53 & 0.65 & 0.000 & -0.65 & 0.76 & 0.000 \\
\hline & Iced tea & -0.44 & 0.67 & 0.000 & -0.28 & 0.61 & 0.000 & -0.62 & 0.69 & 0.000 \\
\hline & Fruit drinks & -0.39 & 0.60 & 0.000 & -0.28 & 0.56 & 0.000 & -0.50 & 0.63 & 0.000 \\
\hline & Soda & 0.11 & 0.41 & 0.000 & 0.12 & 0.43 & 0.000 & 0.11 & 0.39 & 0.000 \\
\hline & Energy drinks & 0.89 & 0.70 & 0.000 & 0.89 & 0.73 & 0.000 & 0.88 & 0.68 & 0.000 \\
\hline & Protein shake & 1.01 & 0.85 & 0.000 & 1.07 & 0.80 & 0.000 & 0.95 & 0.90 & 0.000 \\
\hline \multirow{4}{*}{$\begin{array}{l}0 \\
\frac{0}{0} \\
\frac{0}{0} \\
\frac{0}{4}\end{array}$} & Wine & -1.15 & 0.79 & 0.000 & -1.00 & 0.86 & 0.000 & -1.32 & 0.67 & 0.000 \\
\hline & Mixed drinks & -0.65 & 0.79 & 0.000 & -0.54 & 0.77 & 0.000 & -0.76 & 0.80 & 0.000 \\
\hline & Whiskey & 1.30 & 0.72 & 0.000 & 1.37 & 0.71 & 0.000 & 1.23 & 0.72 & 0.000 \\
\hline & Beer & 1.36 & 0.68 & 0.000 & 1.40 & 0.71 & 0.000 & 1.33 & 0.65 & 0.000 \\
\hline
\end{tabular}

To determine if perceptions of gender-drink stereotyping significantly differ by respondent's gender, we conducted independent t-tests. The comparison results (See Figure 1) show that both male and female respondents have similar perceptions of gender-based stereotypes of drinks, such that both genders perceive given drinks as masculine or feminine. However, the comparisons of gender-based stereotyped drinks by gender found statistically significant differences $(p<.01)$ between the perceptions of men and women for iced tea, fruit juices, wine, and mixed alcoholic drinks. While both genders have similar perceptions on gender-based drink stereotypes, significant differences indicate that female respondents have stronger perceptions than male respondents.

FIGURE 1

COMPARISONS OF GENDER-BASED DRINK STEREOTYPES BY GENDER

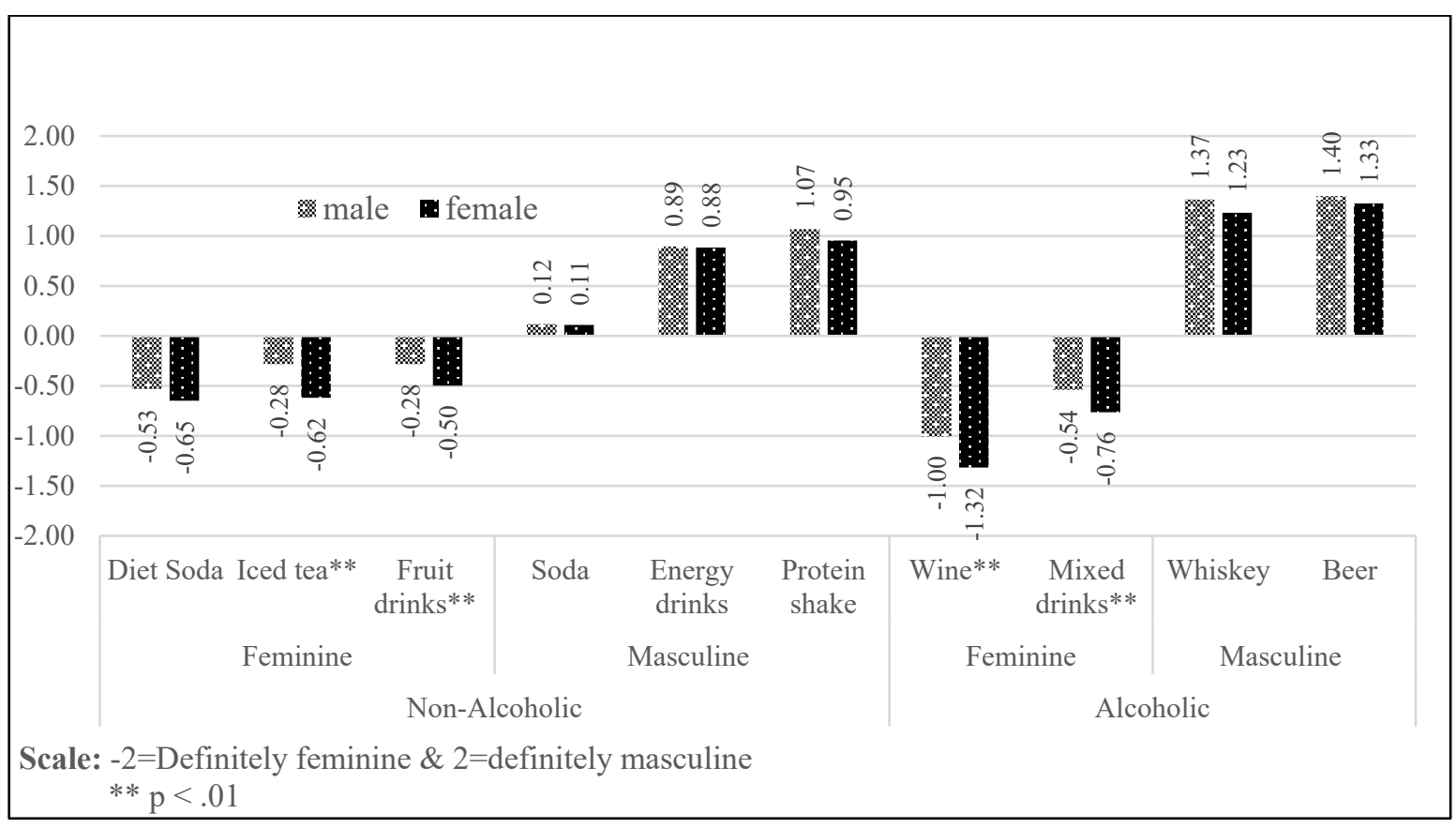

76 Journal of Marketing Development and Competitiveness Vol. 15(4) 2021 
Next, we examined the respondents' consumption tendencies of the gender-based stereotyped drinks. One-sample tests with a test value $=0$ are conducted for all respondents. The results show that (See Table 2) diet soda, fruit juices, energy drinks, mixed (alcoholic) drinks, and whiskey were significantly different from the test value $(\mathrm{p}<.01)$ for all respondents. While the negative significant mean values for diet soda, energy drinks, whisky indicate the respondents collectively are not likely to consume these drinks, the positive significant mean values for fruit juices and mixed alcoholic drinks indicate that respondents are likely to consume these drinks. The test results by gender show that, based on the sign of the mean values, male respondents are unlikely to consume soda, energy drinks, and wine, but are likely to consume fruit drinks, protein shakes, whisky, and beer, whereas female respondents are unlikely to consume diet soda, energy drinks, whisky, and beer, but are likely to consume fruit juices, protein shake, wine, and mixed alcoholic drinks.

TABLE 2

CONSUMPTION INTENTIONS OF GENDER-BASED DRINK STEREOTYPES AMONG THE U.S. MILLENIALS

\begin{tabular}{|c|c|c|c|c|c|c|c|c|c|c|}
\hline & \multicolumn{10}{|c|}{ Respondents } \\
\hline & \multirow[b]{2}{*}{ Drinks } & \multicolumn{3}{|c|}{ All Respondents } & \multicolumn{3}{|l|}{ Male } & \multicolumn{3}{|c|}{ Female } \\
\hline & & Mean & $\begin{array}{l}\text { Std. } \\
\text { Dev. }\end{array}$ & p-sig. & Mean & $\begin{array}{l}\text { Std. } \\
\text { Dev. }\end{array}$ & p-sig. & Mean & $\begin{array}{l}\text { Std. } \\
\text { Dev. }\end{array}$ & $\begin{array}{l}\text { p- } \\
\text { sig. }\end{array}$ \\
\hline \multirow{6}{*}{$\begin{array}{l}: 0 \\
0 \\
\frac{0}{0} \\
\frac{0}{\pi} \\
\frac{\pi}{1} \\
0 \\
z\end{array}$} & Diet Soda & -1.01 & 1.26 & 0.000 & -1.03 & 1.21 & 0.000 & -0.98 & 1.31 & 0.000 \\
\hline & Iced tea & -0.07 & 1.45 & 0.329 & -0.04 & 1.41 & 0.701 & -0.11 & 1.50 & 0.322 \\
\hline & Fruit drinks & 0.47 & 1.32 & 0.000 & 0.55 & 1.27 & 0.000 & 0.38 & 1.37 & 0.000 \\
\hline & Soda & 0.05 & 1.45 & 0.523 & 0.04 & 1.41 & 0.701 & 0.06 & 1.51 & 0.606 \\
\hline & Energy drinks & -0.58 & 1.52 & 0.000 & -0.28 & 1.55 & 0.008 & -0.91 & 1.42 & 0.000 \\
\hline & Protein shake & 0.09 & 1.49 & 0.214 & 0.47 & 1.42 & 0.000 & -0.33 & 1.46 & 0.002 \\
\hline \multirow{4}{*}{$\begin{array}{l}\frac{0}{0} \\
\frac{1}{0} \\
\frac{0}{2} \\
\end{array}$} & Wine & -0.01 & 1.48 & 0.869 & -0.23 & 1.38 & 0.013 & 0.23 & 1.54 & $\overline{0.036}$ \\
\hline & Mixed drinks & 0.33 & 1.43 & 0.000 & 0.13 & 1.39 & 0.161 & 0.55 & 1.45 & 0.000 \\
\hline & Whiskey & -0.23 & 1.54 & 0.003 & 0.26 & 1.51 & 0.011 & -0.76 & 1.39 & 0.000 \\
\hline & Beer & 0.02 & 1.61 & 0.832 & 0.58 & 1.55 & 0.000 & -0.60 & 1.45 & 0.000 \\
\hline
\end{tabular}

The comparisons of the consumption intentions of these drinks by gender (See Figure 2) show no significant differences between the tendencies of males and females for diet soda, iced tea, fruit juices, and soda $(\mathrm{p}>.05)$, but found significant differences $(\mathrm{p}<.01)$ for energy drinks, protein shakes, wine, mixed alcoholic drinks, whiskey and beer that included in the study. Therefore, both genders have significantly different consumption intentions for these stereotyped drinks. It is interesting to note that while both genders are not likely to consume energy drinks, females have a stronger intention not to consume energy drinks and to consume mixed drinks than males. For other drinks with significant differences males and females have an opposite consumption intention. 
FIGURE 2

\section{COMPARISONS OF CONSUMPTION INTENTION OF GENDER-BASED DRINK STEREOTYPES BY GENDER}

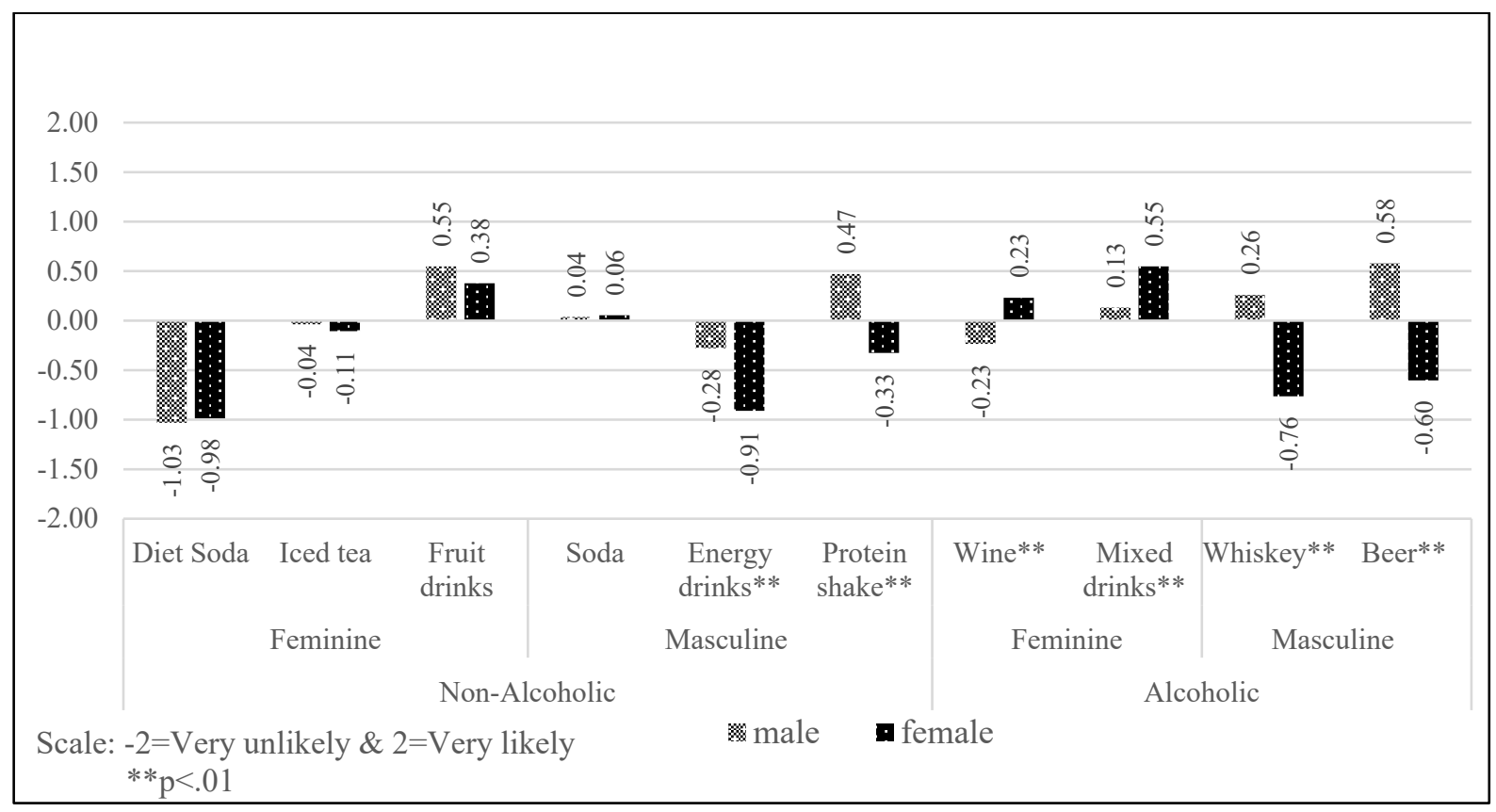

In addition, this study compared the perceptions of gender-based drink stereotypes and their consumption intentions using paired-sample tests. The goal was to determine if there is a congruity between the perception of gender-based drink stereotypes and consumption intentions for both genders. The results for male respondents (See Figure 3) show that there is a congruity between the perception of drink-gender stereotypes and consumption intentions for some of the drinks. For example, male respondents perceive diet soda, wine, fruit juices, and mix alcoholic drinks as feminine drinks and they show a less likelihood of consuming them. They perceive energy drinks as masculine, but not likely to consume, and protein shakes, whiskey, and beer as masculine, and likely to consume them but consumption intention is weaker than the intensity of stereotype perception. The results for female respondents (See Figure 4) also show congruity in drink-gender stereotypes and consumption intentions for some of the drinks. For example, female respondents perceive fruit juices, wine, and mixed alcoholic drinks as feminine, and they are likely to consume them, whereas they perceive energy drinks, protein shakes, whiskey, and beer as masculine and they are less likely to consume them. These results provide some support for the congruity between genderdrink stereotyping and consumption intentions as expected except for diet soda and iced tea. 
FIGURE 3

PERCEPTION OF GENDER-BASED DRINK STEREOTYPES AND CONSUMPTION INTENTIONS BY MALES

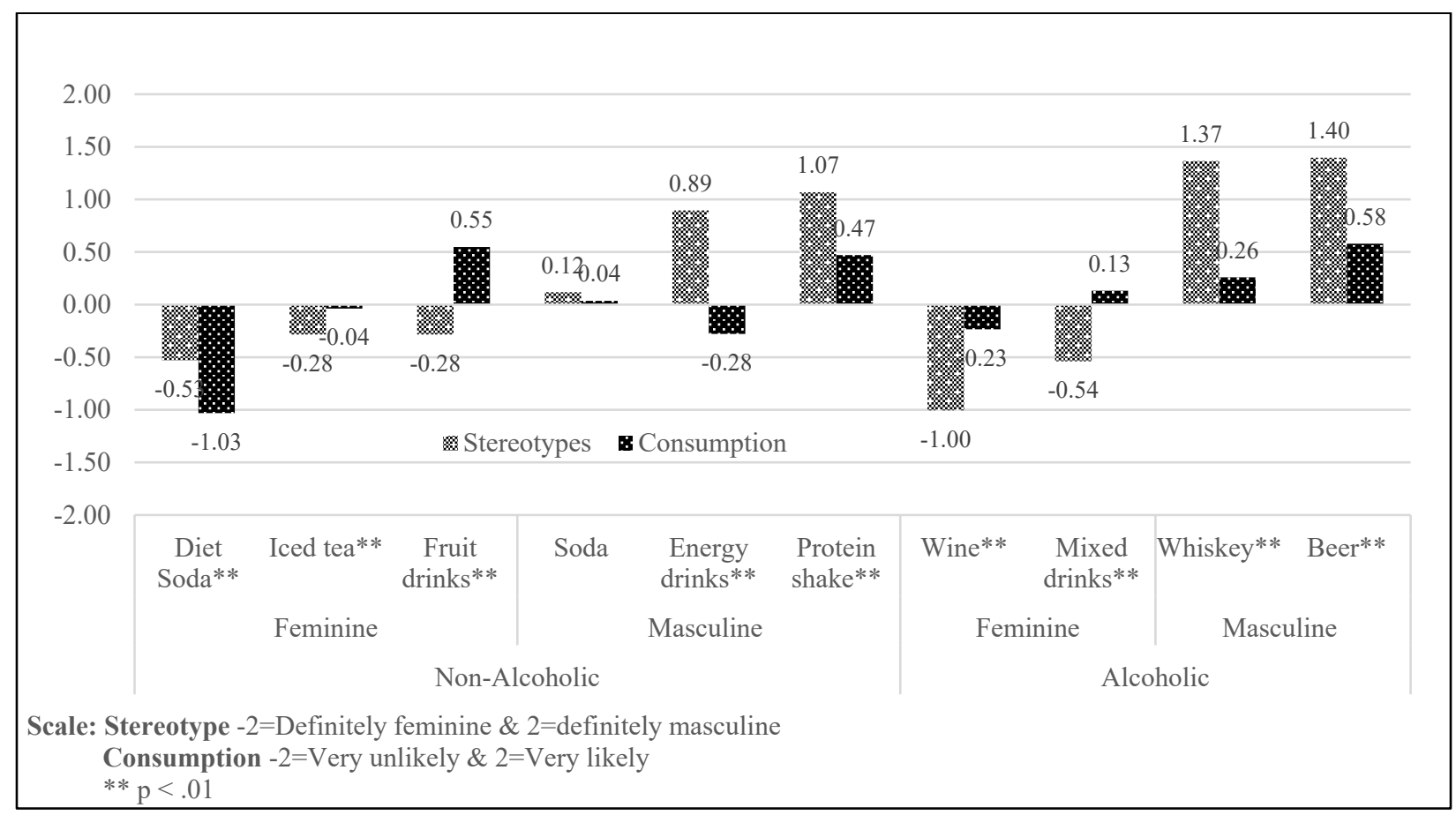

FIGURE 4

PERCEPTION OF OF GENDER-BASED DRINK STEREOTYPES AND CONSUMPTION INTENTIONS BY FEMALES

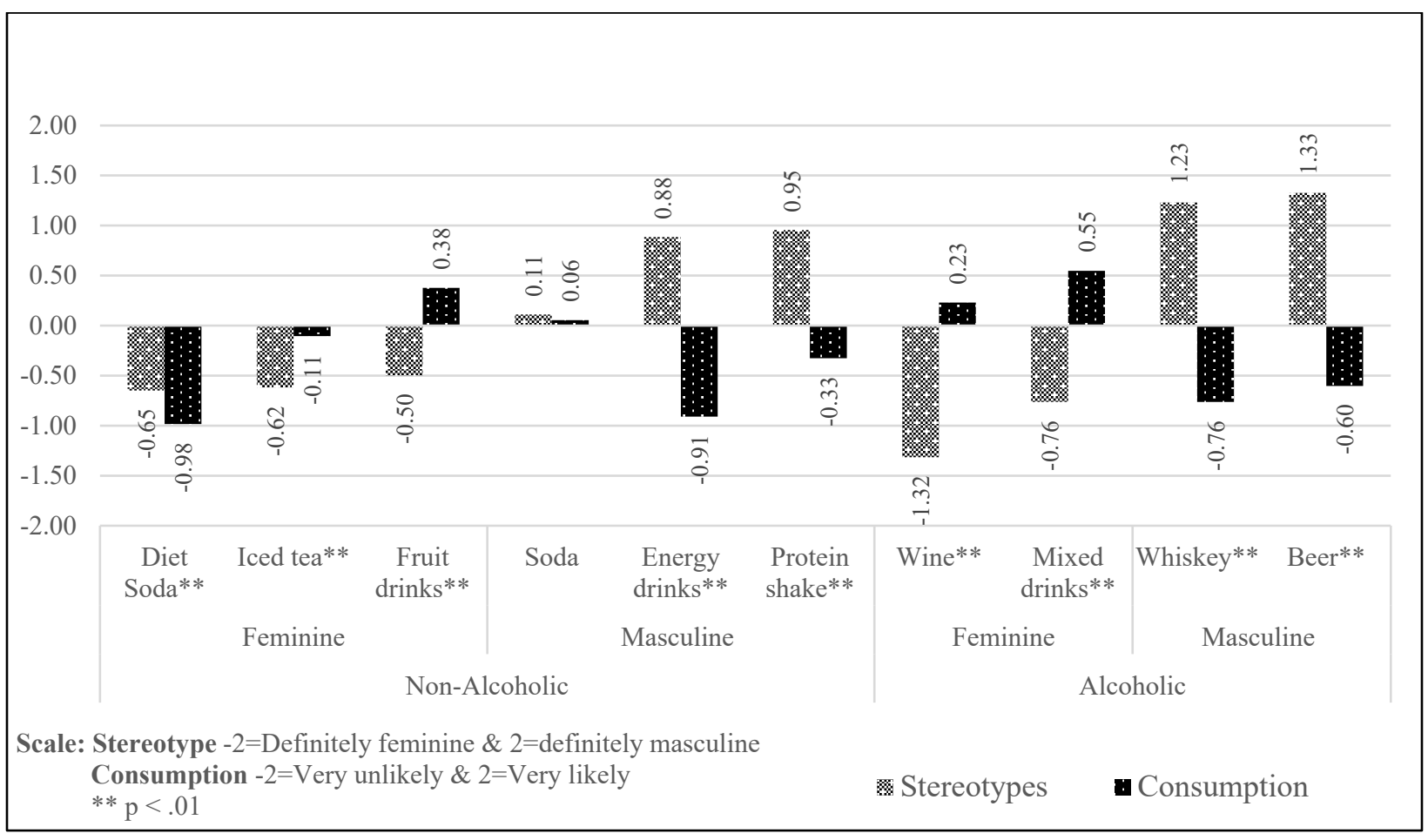




\section{DISCUSSION AND IMPLICATIONS}

This study examines the U.S. millennials' perception of drinks to determine if gender-based drink stereotypes exist and the effects of the gender stereotypes on consumption tendencies of drinks. Results are consistent with the findings of previous studies concerning the perceptions of gender-based food products and some drinks (Bove et al., 2003; Ely et al., 1999; George et al., 1988; McDonald, 1994; McPhail, et al., 2012; Murphy et al., 2005; Sobal, 2005; Wilsnack et al., 2000). The current study reveals that there is a relationship between gender-based drink stereotypes and consumption intentions of these drinks, consistent with the self-congruity theory.

First, the study shows that gender-based stereotyping of drinks exists among millennials. The findings indicate that alcoholic and non-alcoholic drinks are perceived as feminine or masculine for all respondents, as well as by male and female respondents. It is interesting to note that both males and females have similar perceptions about gender-based drink stereotypes. Second, both genders have similar perceptions of genderbased stereotyping of the drinks; however, the comparisons found significant differences between perceptions of male and female respondents regarding some drinks being masculine or feminine. The significant comparisons indicate that females have stronger perceptions of gender identity of the drinks that are consistent with their gender, which is in line with the predictions of the self-congruity theory. As Turnet et al. (2013) highlighted regarding gender-food/drink stereotypes, masculine identity is defined by what they eat or drink, while female identity is supported and negotiated through what they do not eat or drink. Accordingly, females tend to be stricter than males in food and drink consumption. In this context, it can be expected that the tendency of females to perceive feminine drinks as suitable for themselves is higher than males to perceive masculine drinks as appropriate for them.

Regarding the consumption intentions of the stereotyped drinks, this study found that the millennials, collectively or by each gender, are likely to consume certain drinks, will not consume some drinks, and are indifferent in their consumption intentions for some other drinks. When it comes to the tendency of consumption, female millennials select among a wider range of drinks compared to male millennials. The comparisons of consumption intentions by gender show significant differences between male and female millennials' consumption intentions for energy drinks, protein shakes, and wine, mixed alcoholic drinks, whisky, and beer. It is interesting to note that both genders seem to have lower intention to consume the energy drinks, which is perceived as masculine, but females have a significantly stronger intention not to consume it than males, and both genders indicate to consume mixed (alcoholic) drinks that are perceived as a feminine drink, but females have a significantly stronger intention to consume it than males. The other significant differences are consistent with gender stereotyping of the drinks such that consumption intention is congruent with gender-based stereotypes and gender of the consumer. This suggests that gender-based stereotypes of drinks may influence the consumption intentions of certain drinks. With some exceptions, the results indicate that males are more likely to consume masculine drinks and females are more likely to consume feminine drinks, which is consistent with the predictions of congruity theory.

The above findings provide support for the importance of gender-based drink stereotypes on consumption practices, such that that the gendered characteristics of drink products can be an important determinant in selecting drink products. In this regard, the findings of this study have important managerial implications for identifying and effectively segmenting the potential target markets to develop more appealing drinks for each gender. This provides marketers in the beverage sector to effectively position their products and develop advertising and promotional strategies for each gender.

To our best knowledge, this is the first comprehensive study that has empirically identified the genderbased drink stereotypes for both alcoholic and non-alcoholic drinks and the potential effects of genderbased stereotypes on consumption intentions among millennials in the U.S. But these findings should be interpreted within the following limitations. First, further research is needed to compare the results across more drink categories to improve the generalizability of the findings. Second, since millennials are considered as the most diverse generation with similar perceptions and values across cross-cultures, future studies can include religions as a factor potentially influencing consumption practices toward alcoholic drinks. Third, as this study was conducted in one culture, cross-cultural studies could reveal richer 
information, especially for the relationship between gender-based alcoholic drink stereotypes and consumption tendencies. Fourth, the study examines only the perceptions of gender-based drink stereotypes, future studies could ask why certain drinks are perceived as masculine or feminine. The final limitation is that since food and drinks are mainly consumed together, future research that examines the drink-gender stereotype with food consumption could provide a more holistic approach to the food and drink industry and restaurant business.

\section{REFERENCES}

Allen, M. (2017, December 1). Rosé or gin, bro? The Australian Financial Review, p.13.

Basfirinci, C., \& Cilingir Uk, Z. (2017). Gender-based food stereotypes among Turkish university students. Young Consumers, 18(3), 223-244.

Bourdieu, P. (1984). Distinction: A Social Critique of the Judgement of Taste. Routledge \& Kegan Paul, London.

Bove, C.F., Sobal, J., \& Rauschenbach, B.S. (2003). Food choices among newly married couples: Convergence, conflict, individualism, and projects. Appetite, 40(1), 25-41.

Bristor, J.M., \& Fischer, E. (1993). Feminist thought: Implications for consumer research. Journal of Consumer Research, 19(4), 518-36.

Bussey, K., \& Bandura, A. (1999). Social cognitive theory of gender development and differentiation. Psychological Review, 106(4), 676-713.

Butler, J. (2002). Gender trouble. Routledge, New York and London.

Cavazza, N., Guidetti, M., \& Butera, F. (2015). Ingredients of gender-based stereotypes about food. Indirect influence of food type, portion size and presentation on gendered intentions to eat. Appetite, 91(1), 266-72.

Churchill, G., Jr., \& Iacobucci, D. (2005). Marketing Research: Methodological Foundations (9th ed.). Thomson/South-Western, Mason, OH.

Conway, J. (2020, August 14). Preferred alcoholic beverages in U.S. 2019, by gender. Retrieved from https://www.statista.com/statistics/1042563/gender-preferred-alcoholic-beverages-us/\#: :text $=$ According $\% 20$ to $\% 20 \mathrm{a} \% 202019 \% 20$ survey, their $\% 20$ preferred $\% 20$ type $\% 20$ of $\% 20$ alcohol.

Cooper, B. (2017, March 31). The drinks industry's gender failure - Consumer Trends. just - drinks global news. Bromsgrove.

Counihan, C.M., \& Kaplan, S.L. (2004). Food and gender: Identity and power. Routledge, London.

D'Sylva, A., \& Beagan, B.L. (2011). 'Food is culture, but it's also power': The role of food in ethnic and gender identity construction among Goan Canadian women. Journal of Gender Studies, 20(3), 279-89.

Deliens, T., Clarys, P., De Bourdeaudhuij, I., \& Deforche, B. (2015). Correlates of University Students' Soft and Energy Drink Consumption According to Gender and Residency. Nutrients, 7(8), 6550 6566.

Dempster, S. (2011). I drink, therefore I'm man: Gender discourses, alcohol and the construction of British undergraduate masculinities. Gender and Education, 23(5), 635-653.

Dickens, J., \& Chappell, B. (1977). Food for freud? A study of the sexual polarization of food and food products. Journal of the Market Research Society, 19(2), 76-92.

Diekman, A.B., \& Eagly, A.H. (2000). Stereotypes as dynamic constructs: Women and men of the past, present, and future. Personality and Social Psychology Bulletin, 26(10), 1171-1188.

Drake, C.E., Primeaux, S., \& Thomas, J. (2018). Comparing implicit gender stereotypes between women and men with the implicit relational assessment procedure. Gender Issues, 35(1), 3-20.

Eagly, A.H. (1987). Sex differences in social behavior: A social-role interpretation. Lawrence Erlbaum Associates, New Jersey.

Ekebas-Turedi, C., Cilingir Uk, Z., Basfirinci, C., \& Pinar, M. (2020). A Cross-Cultural Analysis of Gender-Based Food Stereotypes and Consumption Intentions among Millennial Consumers. Journal of International Consumer Marketing, 27, 1-17. 
Ely, M., Hardy, R., Longford, N.T., \& Wadsworth, M.E. (1999). Gender differences in the relationship between alcohol consumption and drink problems are largely accounted for by body water. Alcohol and Alcoholism, 34(6), 894-902.

George, W.H., Gournic, S.J., \& McAfee, M.P. (1988). Perceptions of Postdrinking Female Sexuality: Effects of Gender, Beverage Choice, and Drink Payment. Journal of Applied Social Psychology, 18(15), 1295-1316.

Holtzman, J. (2018). The weakness of sweetness: Masculinity and confectionary in Japan. Food, Culture \& Society, 21(3), 280-295.

Jensen, K.O., \& Holm, L. (1999). Preferences, quantities, and concerns: Socio-cultural perspectives on the gendered consumption of foods. European Journal of Clinical Nutrition, 53, 351-359.

Lupton, D. (1996). Food, the body and the self. London: Sage.

Mandler, G. (1982). The structure of value: Accounting for taste. In M.S. Clark \& S.T. Fiske (Eds.), Affect and cognition: The 17th annual Carnegie symposium (pp. 3-36). Hillsdale, NJ: Erlbaum.

McDonald, M. (Ed.). (1994). Introduction: A social-anthropological view of gender, drink and drugs. Gender, Drink and Drugs, pp. 1-31. Providence, RI: Berg.

McPhail, D., Beagan, B., \& Chapman, G.E. (2012). 'I don't want to be sexist but...' denying and reinscribing gender through food. Food, Culture \& Society, 15(3), 473-489.

Murcott, A. (1983). The sociology of food and eating. England: Gower Publishing.

Murphy, J.G., McDevitt-Murphy, M.E., \& Barnett, N.P. (2005). Drink and be merry? Gender, life satisfaction, and alcohol consumption among college students. Psychology of Addictive Behaviors, 19(2), 184.

Naderi, I., \& Van Steenburg, E. (2018). Me first, then the environment: Young Millennials as green consumers. Young Consumers, 19(3), 280-95.

Neale, L., Robbie, R., \& Martin, B. (2016). Gender identity and brand incongruence: When in doubt, pursue masculinity. Journal of Strategic Marketing, 24(5), 347-59.

Saad, L. (2019, August 9). Liquor Ties Wine as Second-Favorite Adult Beverage in U.S. WELLBEING. Retrieved May 19, 2021, from gallup.com

Sobal, J. (2005). Men, meat, and marriage: Models of masculinity. Food and Foodways, 13(1-2), 135158.

Thompson, C.J., \& Holt, D.B. (2004). How do men grab the phallus? Gender tourism in everyday consumption. Journal of Consumer Culture, 4(3), 313-338.

Turner, K., Ferguson, S., Craig, J., Jeffries, A., \& Beaton, S. (2013). Gendered identity negotiations through food consumption. Young Consumers, 14(3), 280-8.

Ulrich, I., \& Tissier-Desbordes, E. (2018). “A feminine brand? Never!” Brands as gender threats for "resistant" masculinities. Qualitative Market Research: An International Journal, 21(3), 274-95.

Vartanian, L.R., Herman, C.P., \& Polivy, J. (2007). Consumption stereotypes and impression management: How you are what you eat. Appetite, 48(3), 265-77.

Wilsnack, R.W., Vogeltanz, N.D., Wilsnack, S.C., \& Harris, T.R. (2000). Gender differences in alcohol consumption and adverse drinking consequences: Cross-cultural patterns. Addiction, 95(2), $251-$ 265.

Young, M.E., Mizzau, M., Mai, N.T., Sirisegaram, A., \& Wilson, M. (2009). Food for thought. What you eat depends on your sex and eating companions. Appetite, 53(2), 268-71. 